\title{
NUTRITIONAL ANAEMIA IN AN INDUSTRIAL DISTRICT *
}

\author{
BY \\ JAMES H. HUTCHISON, M.B., F.R.F.P.S., M.R.C.P. \\ Assistant Physician, Royal Hospital for Sick Children, Glasgow
}

The incidence of nutritional anaemia in infancy has aroused considerable interest in recent years, and its recognition and proper treatment are matters of national concern. Since attention was drawn to the frequency of this form of anaemia during infancy by Mackay (1931) many workers have studied the problem, mainly from the aspects of diagnosis and treatment. Apart from the work of Mackay, there have been few investigations into its incidence in this country (Davidson et al., 1935 ; Findlay, 1937 ; Fullerton, 1937 ; Colver, 1938). It is important that this aspect be further studied, partly because of its importance in the social welfare of the infant and partly because of the light it throws on the etiology of iron-deficiency anaemia as a whole.

The present investigations were made to determine the incidence of the iron-deficiency anaemia of infancy in a large industrial area of Glasgow. Haemoglobin estimations were made on 300 infants of all ages up to one year. These infants were all under the supervision of a Welfare Clinic in Govan, a densely populated district. They did not receive iron supplements to their diets, and were regarded by their mothers as healthy. The haemoglobin estimations were all carried out by the same observer, using a standardized Haldane haemoglobinometer. The blood was taken from the heel, the same two-edged stilette being used for every case.

The present results have been compared with the curve suggested by Mackay $(1931,1933 a)$ as representing the normal haemoglobin levels for the first year of life. The figures given by Mackay for normal values were obtained as follows : the values at two weeks to one month, one to two months and two to three months were averages for groups of breast-fed babies living in their own homes ; those for three to four months of age and upwards were based on haemoglobin values obtained with iron treatment, because it was assumed that these values would more truly represent the optimum than the lower values obtained at this age from babies without treatment. Josephs (1936) criticizes the view of Mackay (1931) that merely because iron raised the haemoglobin level, values below this should be regarded as indicative of iron deficiency. An effective reply would seem to be that not only does iron raise

* This work was carried out during the tenure of a McCunn Medical Research Scholarship. 
the haemoglobin level, it also diminishes the incidence of infection and increases the average gain in weight (Mackay, 1928) ; in short, it assists in the maintenance of perfect health. Furthermore, the curve obtained by Merritt and Davidson (1933) from haemoglobin values obtained from babies in New York City (where there is apparently little tendency for infants to become anaemic) is 'strictly parallel' to Mackay's standard normal haemoglobin curve.

\section{Results of investigation}

In fig. 1 the results obtained in the present series of 300 infants are presented. The individual estimations are plotted in relation to Mackay's normal haemoglobin curve. The well-known trend of the haemoglobin level, which falls rapidly during the first two months of life, is clearly shown; it should also be noted that the majority of haemoglobin estimations during the first ten weeks of life fall into close proximity to the normal curve for that period. From the fifth month onwards, however, the individual values with few exceptions fall below the normal, frequently by as much as 15 to 30 per cent. This high incidence of anaemia among infants of the working class agrees closely with the findings of other workers in this country (Fullerton, 1937 ; Mackay, 1931 ; Colver, 1938). In fig. 2 is shown the average haemoglobin value at each month of age of the 300 infants studied. During the half to one month age period the haemoglobin percentage averages 100.5 per cent. ; it falls rapidly, maintaining a close relationship to the normal curve, so that by two to three months it reaches 72.5 per cent. For the next three months it rises slightly, reaching an average level of 75.6 per cent. at five to six months old. Thereafter it drops slowly to 71 per cent. at nine to ten months and is constantly more than 10 per cent. below the normal value of 86 per cent. These graphs show in a striking manner that it is only after the first six months of life that anaemia becomes so common. Taking a haemoglobin level of 10 per cent. or more below Mackay's normal as indicating anaemia, only 25.3 per cent. of infants under three months and 25.3 per cent. in the three to six month age period appeared to be anaemic, while in the age periods six to nine months and nine to twelve months, 70.7 per cent. and 70.0 per cent. respectively showed anaemia. These results are similar to those of Mackay (1933a) and Fullerton (1937). They differ from those of Findlay (1937), who found no evidence of anaemia in sick children in the East End of London. Findlay's cases, however, were hospital patients including probably many who were under weight and in whom the haemoglobin values were likely to be higher than in rapidly growing infants of the same ages.

The present series contains no haemoglobin values for the first two weeks of life. It is known, however, that the haemoglobin level is high at birth-143 per cent. (Mackay, 1933a) ; thereafter it falls rapidly till it reaches 106 per cent. at half to one month. This fall is the result of haemolysis in response to the sudden rise in oxygen tension of the infant's blood at birth (Mackay, 1933b), when the lung takes the place of the placenta as a medium of oxygenation.

As has been noted, the haemoglobin level continues to fall until about the third month of life, in some cases reaching remarkably low levels (fig. 1). There 
Hammoglobin Percentage in 300 Infants Referred TO ACE

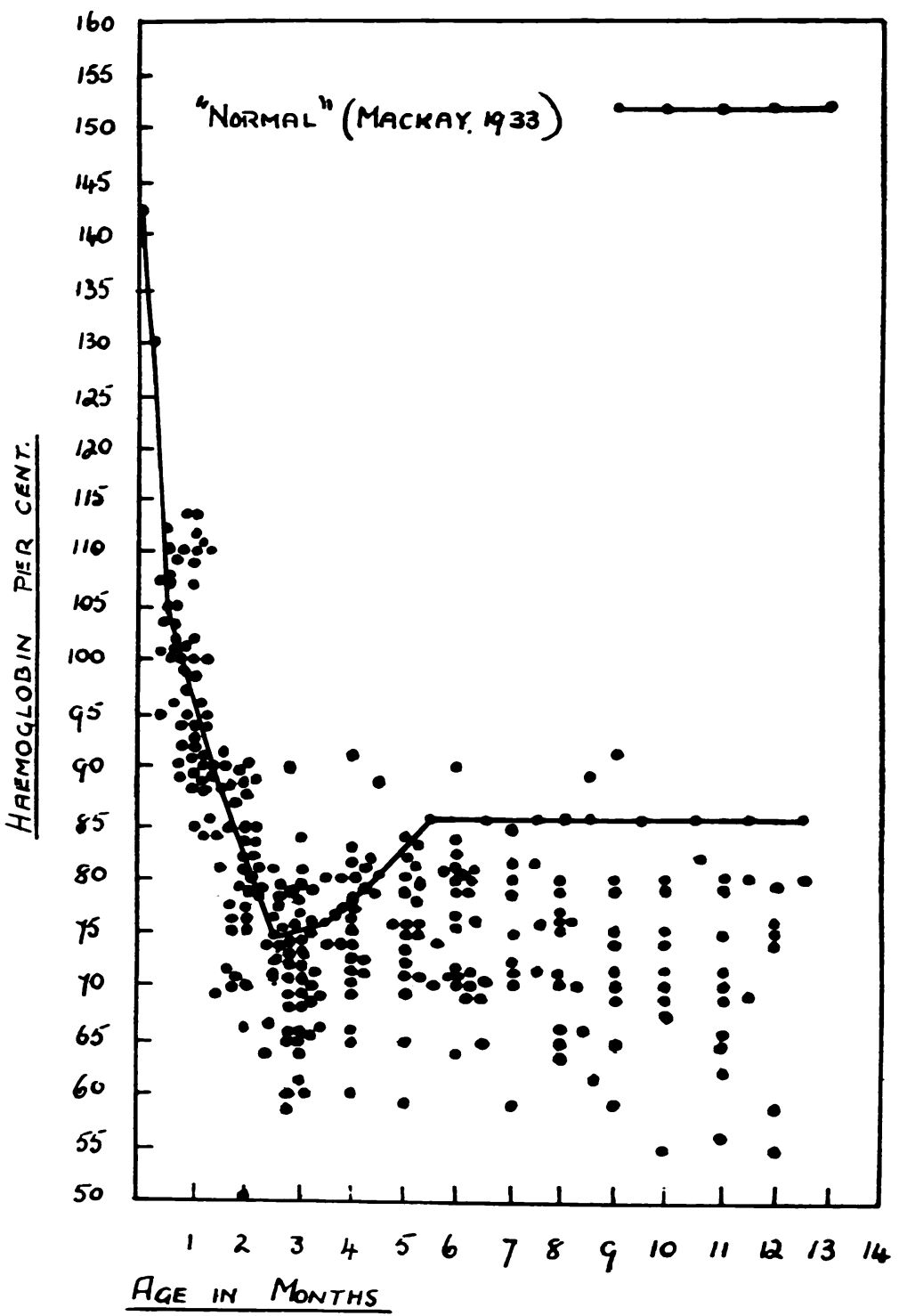

Fig. 1. 
Averace Haemoclobin Values for each Month of the FIRST YEAR OF LIFE

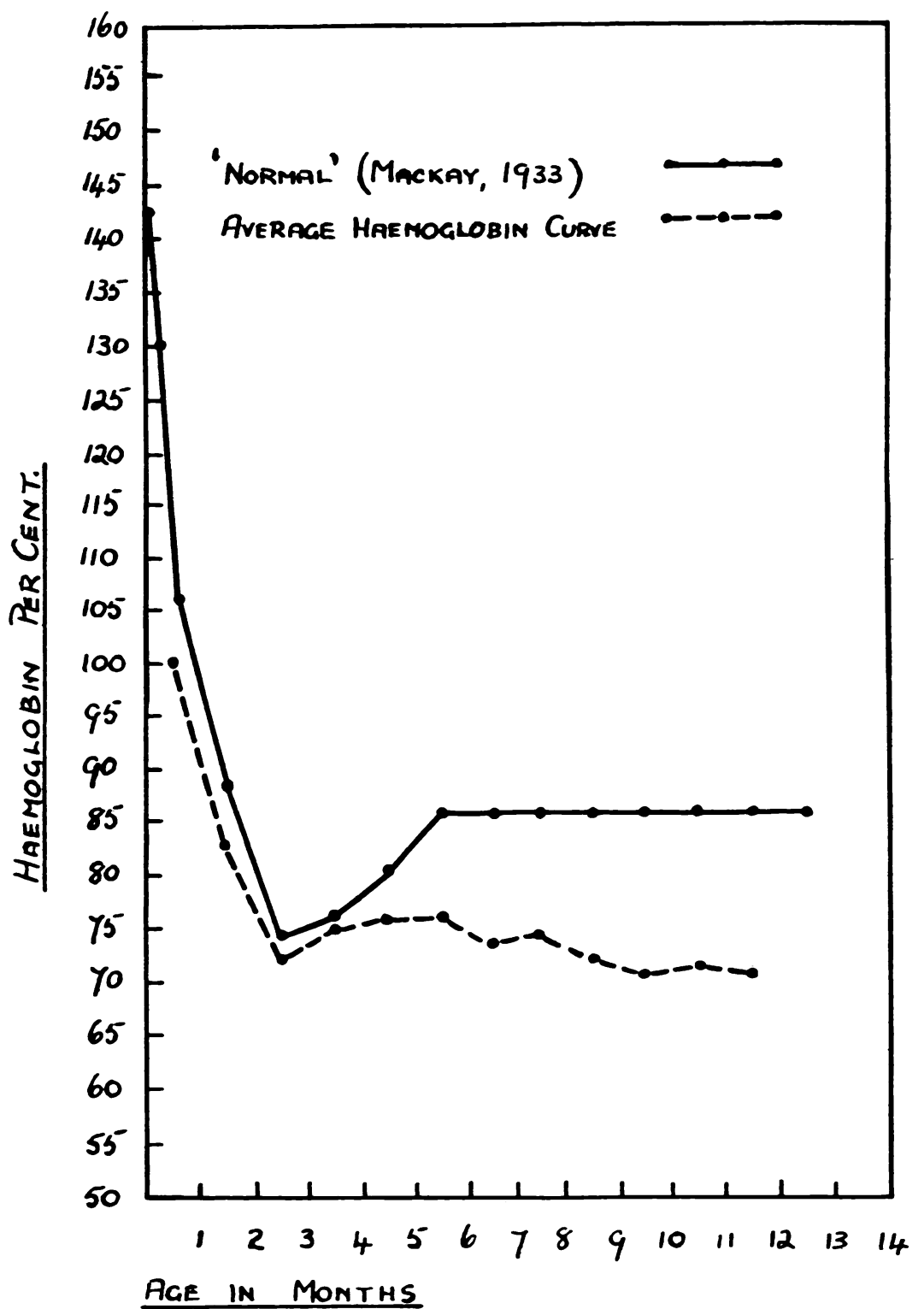

Fig. 2. 
appears to be little doubt that this fall is due to continued haemolysis and must be considered physiological. That iron deficiency does not play a part is shown by the following facts :

(1) Iron does not prevent the fall in haemoglobin during the first three months (Mackay, 1933b) ; (2) the iron content of the liver increases up till the age of two months (Gladstone, 1932) ; (3) the reductions in red cells and haemoglobin are parallel and the blood does not show the low colour index of iron deficiency (Merritt and Davidson, 1933) ; (4) if iron deficiency were a factor, then babies who grow most rapidly would show the lowest haemoglobin levels, which is in fact not the case (Mackay, 1931). Hampson (1928) found an excessive bilirubinaemia until one month of age, and suggests that the haemolysis in the early weeks of life is controlled by the presence of an anti-haemolytic hormone. Josephs (1932), however, regards the fall in haemoglobin to be due to diminution in the rate of haematopoiesis rather than to increased destruction of the blood, putting forward as evidence the fact that administration of iron during the first three months of life has no influence on the reticulocytes, nor is it capable of arresting the fall in haemoglobin and red cells. Of possible significance in this connexion is the finding of Trought (1932) that in the placenta and blood of the new-born infant there is a proportion of haemoglobin differing in some way from that of the adult. This haemoglobin-alpha' persists in the circulation at least till six weeks, i.e. during the time of the most rapid fall in haemoglobin. It is not known if this ' haemoglobin-alpha' has any effect on the resistance of the red cells to haemolysis. Of some interest is the finding (table 1) that by two to three months it is in babies of low birth weight that the haemoglobin has fallen to the lowest levels, in spite of the fact that the lower the birth weight the higher the average haemoglobin level at birth (Mackay, 1933b). Thus babies of the lowest birth weight have the most rapid falls in haemoglobin values during the early months.

TABLE 1

AVERAGE HAEMOGLOBIN VALUES FOR FIRST YEAR OF LIFE REFERRED TO BIRTH WEIGHT

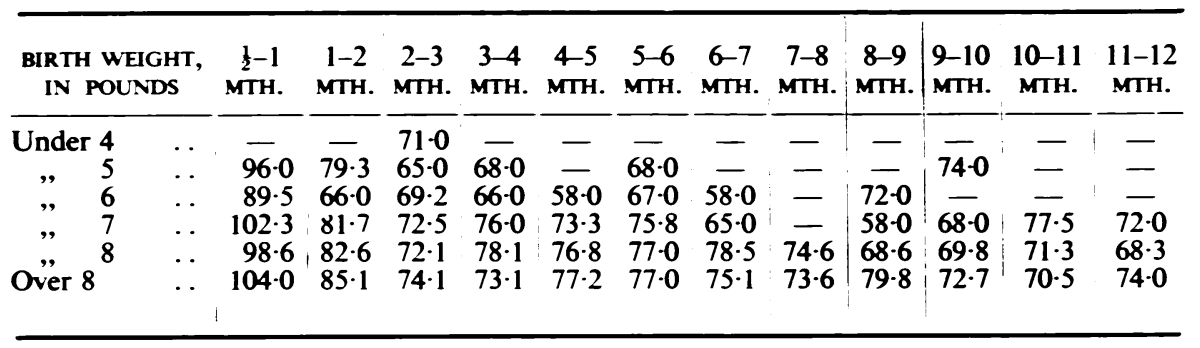

A likely explanation of the rise in haemoglobin values between the third and sixth months (fig. 2) has been given by Gladstone (1932). He found that the iron content of the liver increased steadily till the age of two months while haemolysis was in progress. Thereafter it diminished, until at four months it had returned to the birth level. This is taken to indicate that after the age of two to three months, when haemolysis is at an end, the stored iron is released for haemoglobin formation, and that this store is exhausted about the age of six months, after which time iron-deficiency anaemia begins to appear. Mackay 
$(1931,1933 a)$ has shown that the administration of iron can produce a higher average value at four months than that obtained in the present series (fig. 2), which suggests that sometimes the need for extra iron occurs as early as three months.

Following the slight rise in haemoglobin values during the third, fourth and fifth months the curve falls gradually (fig. 2). On the other hand, the administration of iron from the age of two months produces an average haemoglobin value of 86 per cent. (Mackay, 1933a) throughout the second six months of life, and the infants so treated show a lower morbidity rate. In view of these facts there can be little doubt that the low values obtained in the present series for infants over five months of age (fig. 1) find their explanation in a deficiency of iron. There remains to discuss the explanation of this deficiency.

\section{Causes of iron deficiency}

Deficient ante-natal storage of iron.-It is the view of many workers that though the foetus is able to draw upon the mother for all blood-forming materials for its own immediate needs, irrespective of the condition of the maternal blood, infants born to anaemic mothers are unable subsequently to maintain a normal haemoglobin level during the first year of life (Strauss, 1933 ; Mackay, 1931 ; Paxton, 1936). The Birmingham workers are of the opinion that ante-natal storage of iron may be deficient to such a degree as to produce a congenital nutritional anaemia (Parsons, 1932 ; Parsons and Hawksley, 1933). This opinion appears to be based entirely on a history, from the mothers, of pallor at birth and on ability to produce an iron-deficiency anaemia in the new-born rat (Parsons and Hickmans, 1933). They put forward the suggestion that some mothers, who may not themselves exhibit hypochromic anaemia, have the power to retain their iron to the detriment of the foetus (Neale and Hawksley, 1933). Most authorities agree, however, that the haemoglobin level at birth bears no relation to maternal anaemia. Acting on this assumption and considering iron-deficiency anaemia from a quantitative aspect, Fullerton (1937) has concluded, from a convincing series of calculations, that the iron content of the new-born infant is independent of that of the mother. The same worker in a previous paper showed that the iron drain by the foetus is not sufficiently large to cause a marked effect on the maternal iron content (Fullerton, 1936).

Deficient post-matal supply.-It is generally agreed that the iron content of cow's milk is lower than that of breast milk (Peterson and Elvehjem, 1928 ; Cunningham, 1931 ; Wallgren, 1932), although there is marked variation in the figures obtained by different workers and conclusions based on this supposition have as yet but poor foundations. Nevertheless in the present series the average haemoglobin curve obtained from breast-fed infants shows constantly higher values than the curve of the bottle-fed infants save for the five to six months age period (fig. 3). The average value for the eight to nine months ageperiod in the breast-fed group is seen to be 81 per cent.; this figure is probably erroneous, as only two of the breast-fed infants fell into this age group. This 
Average Haemoglobin Value of Breast-fed Infants Compared WITH VALUES FOR ARTIFICIALLY-FED INFANTS.

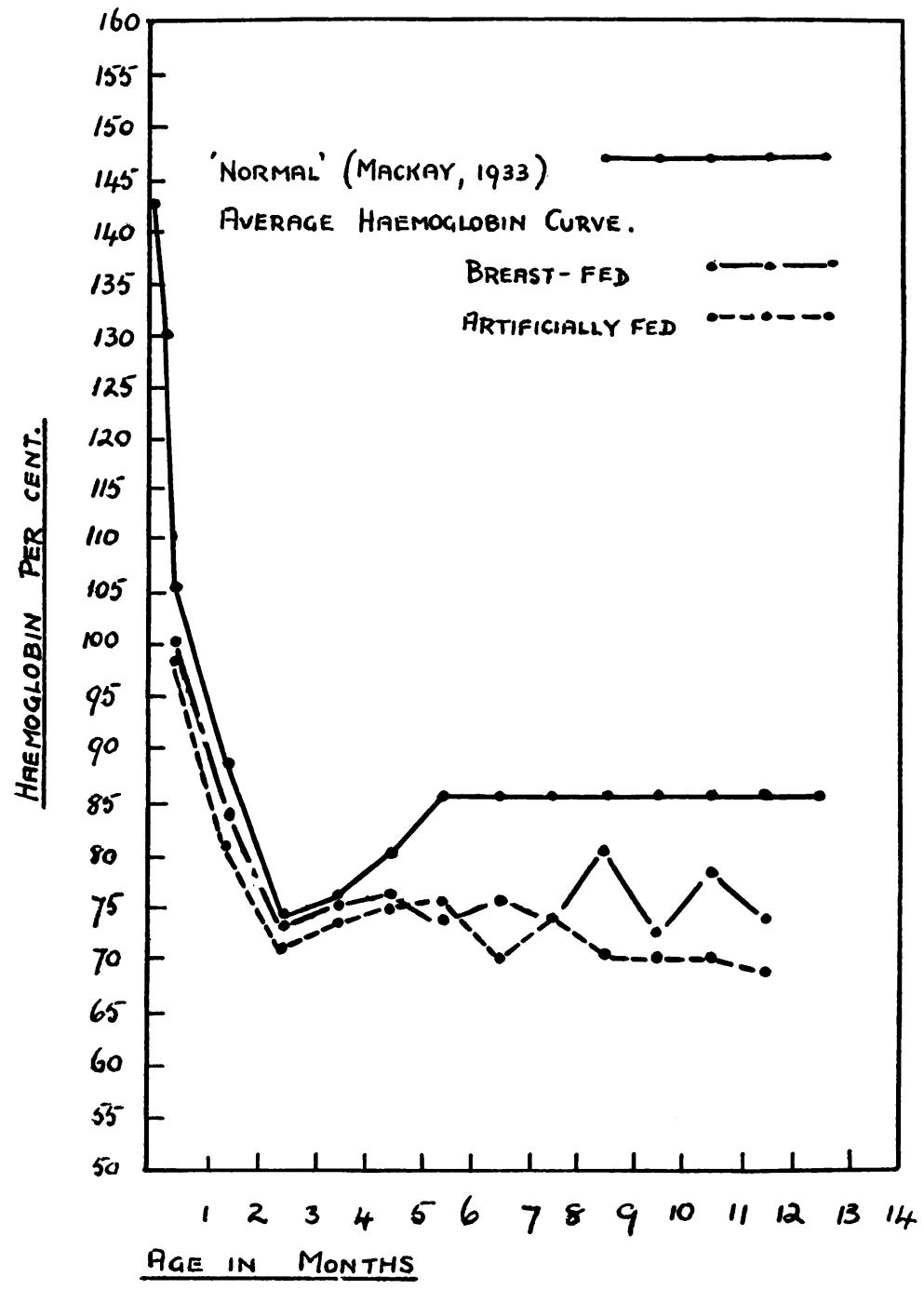

FIG. 3. 
difference between the breast-fed and bottle-fed infants is less marked in the present series than was found by Mackay (1931) and Fullerton (1937). Although it has been suggested that the relatively high values found in the breastfed infants are due to the higher iron content of human milk, it should be noted that this hypothesis does not explain why the bottle-fed infants showed lower values as early as the age of half to one month, a time when the administration of iron does not affect the fall in the haemoglobin content of the blood. A possible explanation lies in the fact that in the present series there were more premature babies and infants of low birth weight (under $6 \mathrm{lb}$.) in the first three months than during the rest of the year, and it is known that such babies have a more rapid fall in haemoglobin, are more likely to be bottle-fed, and have a lesser expectation of continued life. For this reason the curve for bottle-fed infants under three months was made up from a group containing more prematures and infants small at birth than the group of breast-fed infants. Consequently the haemoglobin curve of the bottle-fed group tends to be lower than that of the breast-fed group. Josephs (1934) found a positive iron balance of about 6 milligrammes per month in bottle-fed infants, and calculated that an exclusive milk diet cannot cause anaemia on the basis of its low iron content alone. Langstein and Edelstein found a similar retention of iron in infants fed on human milk. It would however seem that, although the low iron content of milk, prolonged milk feeding and delayed institution of mixed feeding are likely to be potent factors in the production of iron-deficiency anaemia, there is little evidence to explain why the bottle-fed infant should have a greater tendency to become anaemic than the breast-fed infant. At the same time the present results (fig. 3) and those of others clearly demonstrate that this tendency is in fact present, and it is only possible to conclude that the anaemia is dependent in part on factors influencing iron utilization or iron storage which are not yet understood.

Birth weight.- It was found in the present series (table 1) that during the second half of the first year of life, infants of low birth weight had on the whole a lower haemoglobin level than infants weighing $7 \mathrm{lb}$. and upwards at birth. This finding is in agreement with those of other workers (Kunckel, 1915; Mackay, 1931 ; Abt and Nagel, 1932 ; Magnusson, 1935 ; Fullerton, 1937). The frequency of nutritional anaemia in premature infants and twins (Parsons and Hawksley, 1933) is a direct consequence of low birth weight. The tendency for the development of iron deficiency in infants small at birth depends on the fact that infants of low birth weight grow more rapidly in relation to birth weight than infants of normal weight, having at the same time a lower absolute iron content because of a smaller blood volume and a lesser iron store in the liver. The correlation between the haemoglobin level and the rate of growth has been stressed by Mackay (1931), Josephs (1934) and Fullerton (1937). This also applies to premature infants and twins. It has been frequently stated that as deposition of iron in the liver occurs most rapidly in the last three months of gestation (Hugounenq, 1899), early exhaustion of the foetal stores of iron explains the frequency of anaemia in premature infants in whom the period of iron storage has been cut short, and in twins in whom the available iron has to 
be shared. Gladstone (1932) has pointed out, however, that although the acquisition of iron by the foetus is greater during the last four months of intrauterine life than during the first six, the foetal gain in weight during the last three months is greater than during the first seven. Thus during foetal life the increase in total iron content is not more rapid than the increase in total weight, so that premature babies are in relation to their weight almost as well supplied with iron as the full-time baby. It would appear that the greater tendency for anaemia to develop in babies small at birth is the result of relatively rapid growth in weight together with excessive haemolysis in the first two to three months of life (vide supra).

Infections.-The occurrence of a hypochromic anaemia in association with acute and chronic infections is well recognized (Collins, 1935; Minot and Heath, 1932 ; Sturgis et al., 1935 ; Vaughan, 1936). Fullerton (1937) and Josephs (1934) are of the opinion that infection is an important etiological factor in the iron-deficiency anaemia of infancy. In table 2 are found the average haemoglobin values in the present series arranged according to whether or not there was a history of infections. The infections comprised mainly mild gastro-intestinal and respiratory diseases and the exanthemata. Fiftyfive per cent. of the infants had a history of one or more infections. It is seen that there is little difference in the haemoglobin values of the two groups, a result which at first appears surprising. The figures cannot be taken as reliable, however, as the histories of the infections were obtained from the mothers who were not all of average intelligence. Attacking this problem from another aspect, the author has found that severe infections have an adverse influence in the utilization of iron for haemoglobin synthesis (unpublished), and that severe illnesses are frequently followed by anaemia. Mackay (1928) has observed an increased susceptibility to infections on the part of anaemic infants, and it seems probable that in this way a vicious circle may be established-infection causing anaemia and anaemia predisposing to infection. Fullerton's (1937) results leave little doubt that infections may cause marked falls in the haemoglobin level even during iron therapy.

TABLE 2

AVERAGE HAEMOGLOBIN VALUES ACCORDING TO HISTORY OF INFECTIONS

\begin{tabular}{|c|c|c|c|c|c|c|c|}
\hline & $\begin{array}{c}5-6 \\
\text { MONTHS }\end{array}$ & $\begin{array}{c}6-7 \\
\text { MONTHS }\end{array}$ & $\begin{array}{c}7-8 \\
\text { MONTHS }\end{array}$ & $\begin{array}{c}8-9 \\
\text { MONTHS }\end{array}$ & $\begin{array}{c}9-10 \\
\text { MONTHS }\end{array}$ & $\begin{array}{c}10-11 \\
\text { MONTHS }\end{array}$ & $\begin{array}{c}11-12 \\
\text { MONTHS }\end{array}$ \\
\hline No history of infections & 76 & 75 & $71 \cdot 6$ & 72 & $67 \cdot 8$ & $72 \cdot 2$ & 71 \\
\hline History of infections .. & 74 & $73 \cdot 5$ & 75 & $72 \cdot 9$ & $73 \cdot 6$ & $71 \cdot 7$ & $72 \cdot 5$ \\
\hline
\end{tabular}

\section{Prophylaxis}

In view of the high incidence of iron-deficiency anaemia in working-class infants the desirability of its prevention must be stressed, not so much on account of the anaemia per se but because of the associated high morbidity and mortality 
rates. Mackay (1931) has found the administration of $4 \frac{1}{2}-9$ grains of ferri et ammon. citras daily from the age of two months an effective measure in preventing anaemia and diminishing the incidence of infections. Alternatively, a dried milk to which iron has been added may be used. Others have tried a more natural but effective prophylactic agent in the addition of foods of high iron content to the infants' diet at a more early age than has been customary in this country (Whitby and Britton, 1935). At the age of four to five months broth, vegetable purée and the yolk of an egg may be added without harmful effect. It would be good if this method of early 'mixed' feeding could be widely adopted.

\section{Summary}

1. A study of 300 infants provides evidence of the prevalence of irondeficiency anaemia during the first year of life. Twenty-six per cent. of the total number of breast-fed infants and 35 per cent. of the bottle-fed infants gave haemoglobin values of at least 10 per cent. below Mackay's normal values for their respective ages. These percentages become much greater if infants under the age of six months be excluded.

2. The principal factors influencing the development of this type of anaemia are discussed. They are : (1) undue prolongation of exclusive milk diet ; (2) low birth weight ; (3) infections.

3. The importance of prophylaxis is stressed and methods of effecting this are discussed.

Thanks are due to the Managers of the Govan Welfare Centre, who provided the facilities for this work, and to the Medical Research Council, who defrayed part of the expenses.

\section{REFERENCES}

Abt, A. F., and Nagel, B. R. (1932). J. Amer. med. Assoc., 98, 2,270.

Collins, D. H. (1935). Lancet, 2, 548.

Colver, T. (1938). Lancet, 1, 245.

Cunningham, I. J. (1931). Biochem. J., 25, 1,267.

Davidson, L. S. P., Fullerton, H. W., and Campbell, R. M. (1935). Brit. med. J., 2, 195.

Findlay, L. (1937). Ibid., 1, 12.

Fullerton, H. W. (1936). Ibid., 2, 577.

- (1937). Arch. Dis. Childh., 12, 91.

Gladstone, S. A. (1932). Amer. J. Dis. Child., 44, 81.

Hampson, A. C. (1928). Guy's Hosp. Rep., 78, 199.

Hugounenq, M. L. (1899). Compt. rend. Soc. de Biol., 51, 337.

Josephs, H. W. (1932). Amer. J. Dis. Child., 43, 1035.

- (1934). Bull. Johns Hopkins Hosp., 55, 259. (1936). Medicine, 15, 307.

Kunckel, D. (1915). Ztschr. f. Kinderh., 13, 101.

Langstein, L., and Edelstein, F. (1932). Quoted by Committee on Growth and Development of the Child, Part III, Nutrition, New York, 239.

Mackay, H. M. M. (1928). Arch. Dis. Childh., 3, 117.

- (1931). Med. Res. Counc. Spec. Rep. Ser., No. 157.

- (1933a). Arch. Dis. Childh., 8, 221.

- (1933b). Loc. cit., 251. 
Magnusson, J. H. (1935). Acta Paediatr., 18, Supp. No. 1, 331.

Merritt, K. K., and Davidson, L. T. (1933). Amer. J. Dis. Child., 46, 990.

Minot, G. R., and Heath, C. W. (1932). Amer. J. med. Sci., 183, 110.

Neale, A. V., and Hawksley, J. C. (1933). Arch. Dis. Childh., 8, 227.

Parsons, L. G. (1932). Acta Paediatr., 13, 378.

Parsons, L. G., and Hickmans, E. M. (1933). Arch. Dis. Childh., 8, 95.

Parsons, L. G., and Hawksley, J. C. (1933). Loc. cit., 117.

Paxton, W. T. W. (1936). Glasgow Med. J., 125, 153.

Peterson, W. H., and Elvehjem, C. A. (1928). J. Biol. Chem., 78, 215.

Strauss, M. B. (1933). J. Clin. Invest., 12, 345.

Sturgis, C. C., Isaacs, R., Goldhammer, S. M., Bethel, F. H., and Farrar, G. E. (1935). Arch. Int. Med., 55, 1001.

Trought, H. (1932). Arch. Dis. Childh., 7, 259.

Vaughan, J. M. (1936). The Anaemias, London, second edition.

Wallgren, A. (1932). Acta Paediatr., 12, 153, 170.

Whitby, L. E. H., and Britton, C. J. C. (1935). Disorders of the Blood, London. 